\title{
Organic Secondary Ion Mass Spectrometry: Signal Enhancement by Water Vapor Injection
}

\author{
Taoufiq Mouhib, Arnaud Delcorte, Claude Poleunis, and \\ Patrick Bertrand \\ Institute of Condensed Matter and Nanosciences-Bio and Soft Matter (IMCN/BSMA), Université catholique \\ de Louvain, Louvain-la-Neuve, Belgium
}

\begin{abstract}
The enhancement of the static secondary ion mass spectrometry (SIMS) signals resulting from the injection, closely to the sample surface, of $\mathrm{H}_{2} \mathrm{O}$ vapor at relatively high-pressure, was investigated for a set of organic materials. While the ion signals are generally improved with increasing $\mathrm{H}_{2} \mathrm{O}$ pressure upon $12 \mathrm{keV} \mathrm{Ga}{ }^{+}$bombardment, a specific enhancement of the protonated ion intensity is clearly demonstrated in each case. For instance, the presence of $\mathrm{H}_{2} \mathrm{O}$ vapor induces an enhancement by one order of magnitude of the $[\mathrm{M}+\mathrm{H}]^{+}$static SIMS intensity for the antioxidant Irgafos 168 and a $\sim 1.5$-fold increase for polymers such as poly(vinyl pyrrolidone). (J Am Soc Mass Spectrom 2010, 21, 2005-2010) (c) 2010 American Society for Mass Spectrometry
\end{abstract}

I $\mathrm{n}$ the last two decades, static SIMS has become one of the most useful techniques for organic, polymeric, and biochemical materials characterization [1-5]. In conjunction with instrumental developments, specific sample preparation procedures have been proposed to improve the molecular signal intensities for organic materials. The utilization of matrices, such as those used in matrix-assisted laser desorption ionization (MALDI), was found to improve sensitivity very significantly by increasing the intensity of the protonated molecular ions [6, 7]. Another protocol, using metal condensation over the organic surface, was called metal assisted-SIMS (MetA-SIMS). It was found to enhance the yields of characteristic ions by one or two orders of magnitude depending on the sample, and even more in some instances [8-10]. With the advent of polyatomic projectiles, such as $\mathrm{SF}_{5}{ }^{+}, \mathrm{C}_{60}{ }^{+}, \mathrm{Bi}_{n}{ }^{+}$, and $\mathrm{Au}_{n}{ }^{+}$, huge molecular ion yield enhancements have been measured (up to 1000-fold increases in signal compared with $\mathrm{Ga}^{+}$ atomic projectiles), leading to a revolution of the field of organic SIMS characterization [11-15]. With the additional molecular depth profiling capabilities of $\mathrm{SF}_{5}{ }^{+}$and $\mathrm{C}_{60}{ }^{+}$cluster beams, one can now hope to relate the performance characteristics of organic devices to their surface molecular composition in a much more quantitative way. Nevertheless, in spite of these multiple improvements, useful molecular signals remain low for the next generation of organic SIMS applications, involving nanometer-scale 3D molecular characterization of surfaces. Indeed, if some current cluster beams can be focused to a diameter of $100 \mathrm{~nm}$ or less, the corresponding reduction of the interrogated volume raises again

Address reprint requests to Dr. T. Mouhib, Institute of Condensed Matter and Nanosciences-Bio and Soft Matter (IMCN/BSMA), Université catholique de Louvain, Croix du Sud, 1 bte 3; Bât. Boltzmann (a1), B-1348 Louvain-la-Neuve, Belgium. E-mail: taoufiq.mouhib@uclouvain.be. the level of sensitivity needed for analysis. Therefore, what the field needs today is a method that can be associated to cluster beam bombardment to provide an additional level of molecular signal enhancement.

Since the emergence of SIMS, it has been shown that the ionization probability depends highly on the chemical environment [16]. This effect is routinely used in SIMS depth profiling by applying oxygen sputtering to increase positive ion yields and cesium sputtering to increase negative ion yields $[17,18]$. In those cases, the secondary ion yields strongly increase with the concentration of the reactive species. Ions can also be formed by the recombination of a sputtered neutral atom $\mathrm{M}$ or cluster with an emitted $\mathrm{Cs}^{+}$ion giving a $\mathrm{MCs}^{+}$secondary ion, an effect that is used for quantitative depth profiling [19]. It has also been recognized in inorganic SIMS that the secondary ion yield is high for elements that form a strong ionic bond with oxygen [20], fluorine [21], or chlorine [22]. Following this idea, different gas flooding techniques have been proposed. For instance, Gao et al. [22] and Sielanko et al. [23] found significant secondary ion yield enhancements for many elements, using $\mathrm{CCl}_{4}$ gas flooding combined with oxygen ion bombardment and $\mathrm{CF}_{2} \mathrm{Cl}_{2}$ gas flooding under cesium ion bombardment, respectively. In addition, it is known from the focused ion beam (FIB) milling of organic materials that $\mathrm{H}_{2} \mathrm{O}$ injection at high-pressure increases the sputter rates by a factor of 10 and more [24]. Even the sputtering of diamond is enhanced by $\mathrm{H}_{2} \mathrm{O}$ injection. Finally, the water ice present upon sample freezing of biological materials for SIMS analysis is also believed to be an efficient source of protons for cationization [25-27]. Therefore, flooding the analyzed surface with $\mathrm{H}_{2} \mathrm{O}$ gas appears to be a promising approach to enhance the molecular ion yields in organic SIMS. 
In this article, we report on $\mathrm{H}_{2} \mathrm{O}$ vapor flooding experiments that lead to a significant enhancement of the positive SIMS intensities of a set of organic materials. This new protocol, tested with a $12 \mathrm{keV} \mathrm{Ga}^{+}$primary beam, is easily transferable to other bombardment conditions. The role of the $\mathrm{H}_{2} \mathrm{O}$ pressure in the specific intensity enhancement of protonated ions emitted from a polymer antioxidant and from high-molecular-weight polymers was examined in detail.

\section{Experimental}

\section{Samples}

Various organic molecules, including antioxidant Tris (2,4-di-tert-butylphenyl) phosphite (Irgafos 168) and four polymers (poly(vinyl pyrrolidone), PVP; poly(4vinyl pyridine), P4VP; poly(methyl methacrylate), PMMA; and polystyrene, PS) were dissolved to a concentration of $10 \mathrm{mg} / \mathrm{mL}$ in the appropriate solvent (Table 1$)$ and spin-cast $\left(10,000 \mathrm{rpm}^{-1} ; 4000 \mathrm{rpm} ; 60 \mathrm{~s}\right)$ on a clean $1 \mathrm{~cm} \times 1 \mathrm{~cm}$ silicon wafer. Thickness measurements of the organic films were made using a spectroscopic ellipsometer UVISEL M200, HORIBA Jobin-Yvon (Longjumeau Cedex, France). Resulting organic film thicknesses are shown in Table 1.

\section{TOF-SIMS Instrument}

The secondary ion mass analyses were performed in a Phi-EVANS (Chanhassen, MN, USA) time-of-flight SIMS (TRIFT 1) using a $15 \mathrm{keV} \mathrm{Ga}^{+}$beam $(\sim 1 \mathrm{nA} \mathrm{DC}$ current; $22 \mathrm{~ns}$ pulse width bunched down to $1 \mathrm{~ns} ; 5 \mathrm{kHz}$ repetition rate) with the sample voltage at $3 \mathrm{kV}$ [28]. To improve the measured intensities, the secondary ions were post-accelerated by a high voltage $(7 \mathrm{kV})$ in front of the microchannel plate detector. TOF-SIMS spectra in the mass range $0<\mathrm{m} / \mathrm{z}<1000$ were obtained by collecting the secondary ion signals from $180 \mathrm{~s}$ acquisitions on a $120 \times 120 \mu \mathrm{m}^{2}$ sample area. The total ion fluence accumulated during an acquisition cycle was 8.1 $\times 10^{11}$ ions $/ \mathrm{cm}^{2}$, which ensured the static bombardment conditions. For reproducibility the SIMS measurements were made on three different samples (three measurements on each).

\section{Gas Injection System}

A modification was made in the sample chamber to introduce water vapor closely to the sample surface using a gas injection system, illustrated schematically in Figure 1. The gas injection system and the differential pumping are adapted to reach sufficiently high pressures at the sample surface while the pressure of the chamber remains low. The $\mathrm{H}_{2} \mathrm{O}$ vapor was fed to the sample surface through a $0.5-\mathrm{mm}$-diameter injector needle positioned to within $1 \mathrm{~mm}$ of the sample. To prevent the close proximity of the nozzle to the surface from adversely affecting the secondary ion extraction field and degrading the collection efficiency, the nozzle was electrically grounded. The gas flow from the reservoir was controlled using a needle valve and the gas pressure at the entrance of the injector needle was monitored using a variable leak Granville-Phillips valve (Boulder, CO, USA). The pressure measured at the entrance of the injector was about $1 \times 10^{-3}$ Torr. The real partial pressure at the sample surface during the water vapor flooding might be different from the measured pressure in the chamber, because of the gauge location in the instrument. But at the equilibrium, the measured chamber pressures should be proportional to the pressures at the sample surface, with the ratio remaining constant during the pressure variation. The pressure at the sample should be close to the measured entrance pressure, while the pressure of the chamber remains below $\approx 5 \times 10^{-5}$ Torr.

\section{Results and Discussion}

The goal of this article is to assess the interest of the injection of high-pressure water vapor in the selvedge region of organic samples for SIMS analysis. The choice of the used set samples is motivated by the wish to test the ability of the proposed water vapor protocol to enhance SIMS intensities for both low and high molecular weight organic materials. The discussion is divided in two sections. The first section investigates the case of the quasi-molecular ions of a low molecular weight polymer additive. The second section addresses the effect of the $\mathrm{H}_{2} \mathrm{O}$ gas on the enhancement of the fingerprint ions of high molecular weight polymers. It should be mentioned here that for clean aluminum and silicon substrates, we did not measure any effect of the $\mathrm{H}_{2} \mathrm{O}$ pressure on the characteristic secondary ion yields.

\section{Polymer Additive}

The polymer additive analyzed in the context of this study is the antioxidant Irgafos 168. The absolute intensity of the

Table 1. Description of the samples

\begin{tabular}{llcccc}
\hline \multicolumn{1}{c}{ Molecule } & Acronym & $\mathrm{M}_{\mathrm{w}}(\mathrm{Da})$ & Source & Solvent & Thickness (nm) \\
\hline \hline Irgafos 168 Tris (2,4-di-tert-butylphenyl) phosphite & Irgafos 168 & 647 & Ciba Specialty & Toluene & $103.5 \pm 2.4$ \\
& & & Chemicals Inc. & \\
poly(vinyl pyrrolidone) & PVP & 29000 & Sigma-Aldrich & Ethanol & $106.7 \pm 4.3$ \\
poly(4-vinyl pyridine) & P4VP & 60000 & Sigma-Aldrich & Ethanol & $105.8 \pm 1.8$ \\
poly(methyl methacrylate) & PMMA & 30000 & Sigma-Aldrich & Acetone & $88.7 \pm 1.2$ \\
Polystyrene & PS & 30000 & Sigma-Aldrich & Toluene & $92.4 \pm 1.6$ \\
\hline
\end{tabular}




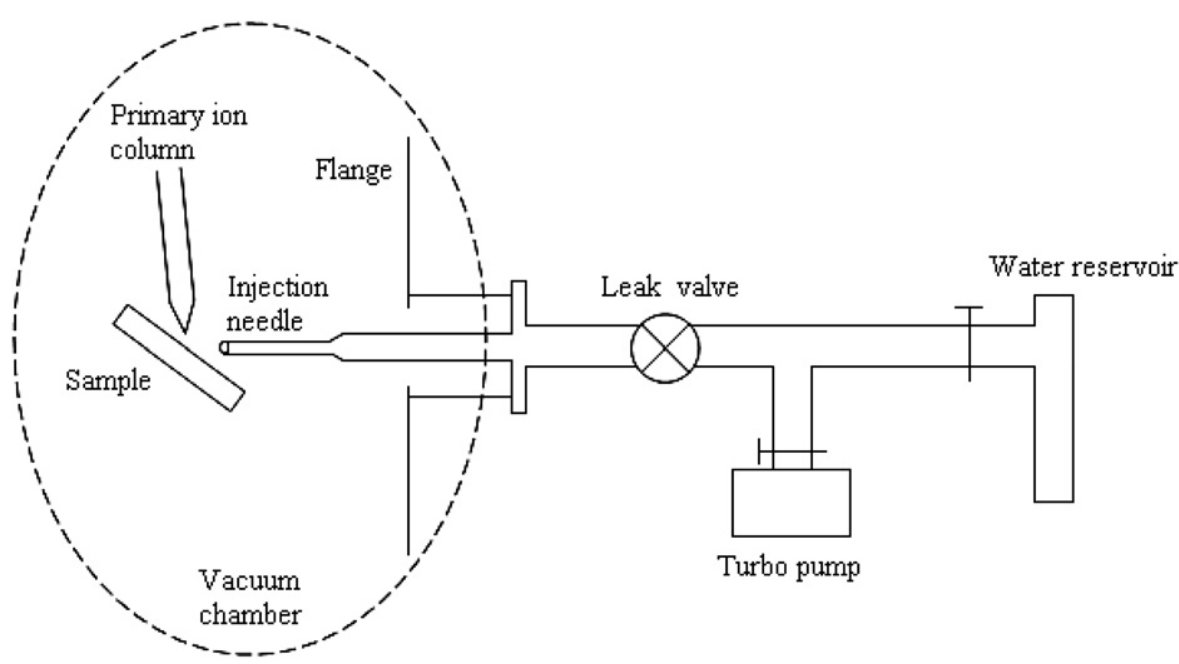

Figure 1. Schematic illustration of the gas injection system.

protonated molecule $[\mathrm{M}+\mathrm{H}]^{+}\left(\mathrm{C}_{42} \mathrm{H}_{64} \mathrm{O}_{3} \mathrm{P}^{+}\right)$, is shown in Figure $2 \mathrm{a}$ as a function of the chamber pressure (which should be proportional to the partial pressure of the $\mathrm{H}_{2} \mathrm{O}$ vapor at the surface sample). The increase of the water vapor pressure induces the increase of the protonated molecule signal until a maximum is reached, at $\sim 10^{-6}$ Torr. At higher pressure, the intensity decreases steeply, which is probably due to the reduction of the mean free path of the emitted ions caused by their interaction with the gas. The absolute $[\mathrm{M}+\mathrm{H}]^{+}$ intensity recorded with decreasing water pressure is also shown. The curves obtained upon raising or decreasing pressure are quite similar, which means that the signal variation is reversible. The reproducibility is reasonably good, even though slight differences are observed in (1) the precise value of the maximum intensity and (2) the measured pressure at the maximum $\left(3.9 \times 10^{-6}\right.$ Torr in the case of increasing pressure and $1.4 \times 10^{-6}$ Torr in the case of decreasing pressure). Those differences can be tentatively explained by two effects. First, the pressure gauge is located at some distance from the surface and, therefore, it does not necessarily provide an instant reflection of the local pressure around the impact point. Second, possibly, after the first experiment conducted with increasing pressure, $\mathrm{H}_{2} \mathrm{O}$ molecules remain adsorbed on the sample surface, thereby increasing the probability of chemical reaction in the impact region.

The observed $\mathrm{H}_{2} \mathrm{O}$ pressure-dependent enhancement of the molecular ion intensities might be explained by an increase of the sputtering yield, as was observed upon FIB milling of organic materials in presence of $\mathrm{H}_{2} \mathrm{O}$ gas, or by specific ionization effects. To obtain some information about the ionization itself, Figure $2 \mathrm{~b}$ shows the pressure dependence of the relative intensities of molecular, protonated, and deprotonated ions emitted from Irgafos 168 in the same conditions. The maximum intensity of the $[\mathrm{M}+\mathrm{H}]^{+}$secondary ion is $\sim 30$ times larger than the intensity measured for normal vacuum conditions (without gas flooding). In comparison, the intensity enhancements of $[\mathrm{M}]^{+}$and $[\mathrm{M}-\mathrm{H}]^{+}$are, respectively, 1.7 and 2 times lower than that of $[\mathrm{M}+\mathrm{H}]^{+}$. This result demonstrates that there is a differential effect of the $\mathrm{H}_{2} \mathrm{O}$ flooding on the intensity of ions that are formed by different ionization mechanisms. It also confirms that the presence of $\mathrm{H}_{2} \mathrm{O}$ favors particularly the formation of protonated molecular ions.

\section{High Molecular Weight Polymers}

All the polymeric materials examined in this study (PVP, P4VP, PMMA, and PS) exhibit quite similar intensity variations of the protonated repeat unit ion $[\mathrm{M}+\mathrm{H}]^{+}$in the presence of $\mathrm{H}_{2} \mathrm{O}$ vapor. The measured enhancement factors are summarized in Table 2. In comparison with the low molecular weight polymer additive, Irgafos 168, they are significantly smaller $(\sim 1.5)$. This is probably due to the specific chemistry of the Irgafos 168. In fact, in the presence of water, such an active phosphite undergoes hydrolysis and produce $\mathrm{H}_{3} \mathrm{PO}_{3}$ molecules, which can act as an additional source of protons [29].

The case of PVP provides a good illustration of the common behavior observed for all the considered polymers. With the same normalization procedure as Figure $2 \mathrm{~b}$, Figure 3 presents the relative intensities of the $[\mathrm{M}-$ $\mathrm{H}]^{+},[\mathrm{M}]^{+}$and $[\mathrm{M}+\mathrm{H}]^{+}$ions of PVP as a function of the $\mathrm{H}_{2} \mathrm{O}$ vapor pressure, under $12 \mathrm{keV} \mathrm{Ga}{ }^{+}$bombardment. The results also show that $\mathrm{H}_{2} \mathrm{O}$ vapor flooding induces a preferential increase of the protonated ion intensity. Therefore, all our results point to a significant influence of the injected $\mathrm{H}_{2} \mathrm{O}$ gas on the protonation reactions occurring in the selvedge of the analyzed materials.

\section{Protonation Mechanism}

To investigate the origin of the protons leading to higher yields of $[\mathrm{M}+\mathrm{H}]^{+}$ions, TOF-SIMS spectra have 


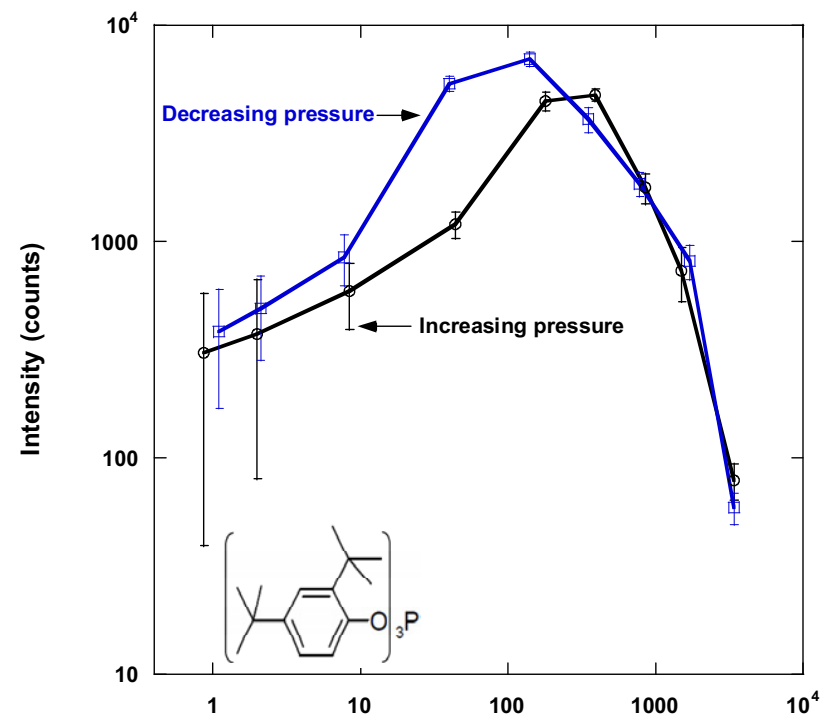

(a)

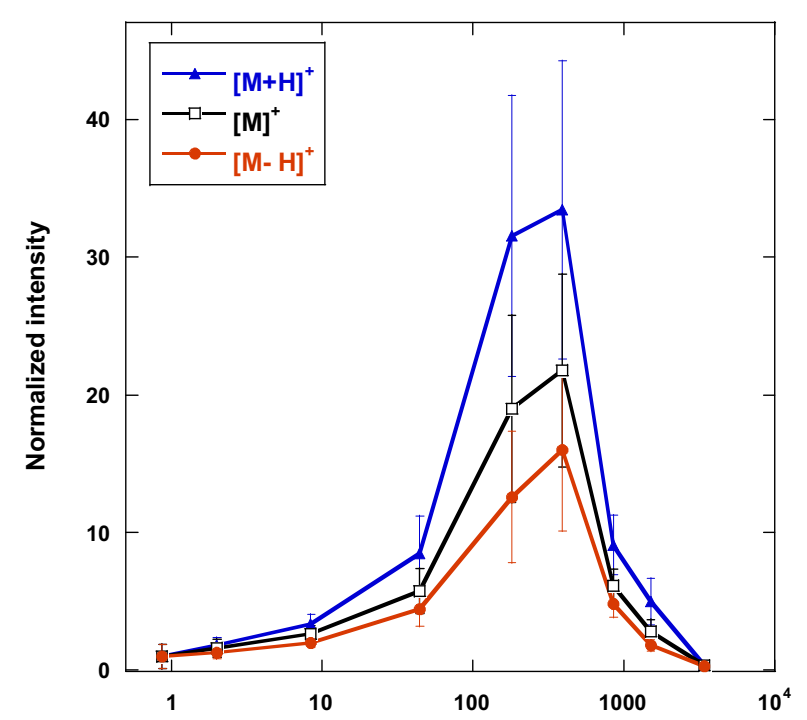

(b)

Chamber pressure ( x 10E-8 Torr)

Figure 2. Effect of $\mathrm{H}_{2} \mathrm{O}$ vapor injection for Irgafos 168. (a) Variation of the absolute intensity of the protonated ion $[\mathrm{M}+\mathrm{H}]^{+}$for increasing water pressure (open squares) and for decreasing water pressure (filled circles). The bottom-left inset shows the chemical formula of Irgafos 168. (b) Relative intensities of the molecular (open square), protonated (filled circle) and deprotonated (filled triangle) ions.

been collected in the presence of $\mathrm{D}_{2} \mathrm{O}$ vapor. The absolute intensity of the deuterated molecule $[\mathrm{M}+\mathrm{D}]^{+}$ as a function of the chamber pressure is shown in

Table 2. Maximum enhancement factors of the protonated repeat unit $[\mathrm{M}+\mathrm{H}]^{+}$of the polymers due to the $\mathrm{H}_{2} \mathrm{O}$ vapor exposure

\begin{tabular}{lc}
\hline Polymer & Enhancement factor \\
\hline \hline PVP & $1.6 \pm 0.1$ \\
P4VP & $1.6 \pm 0.1$ \\
PMMA & $1.4 \pm 0.1$ \\
PS & $1.1 \pm 0.1$ \\
\hline
\end{tabular}

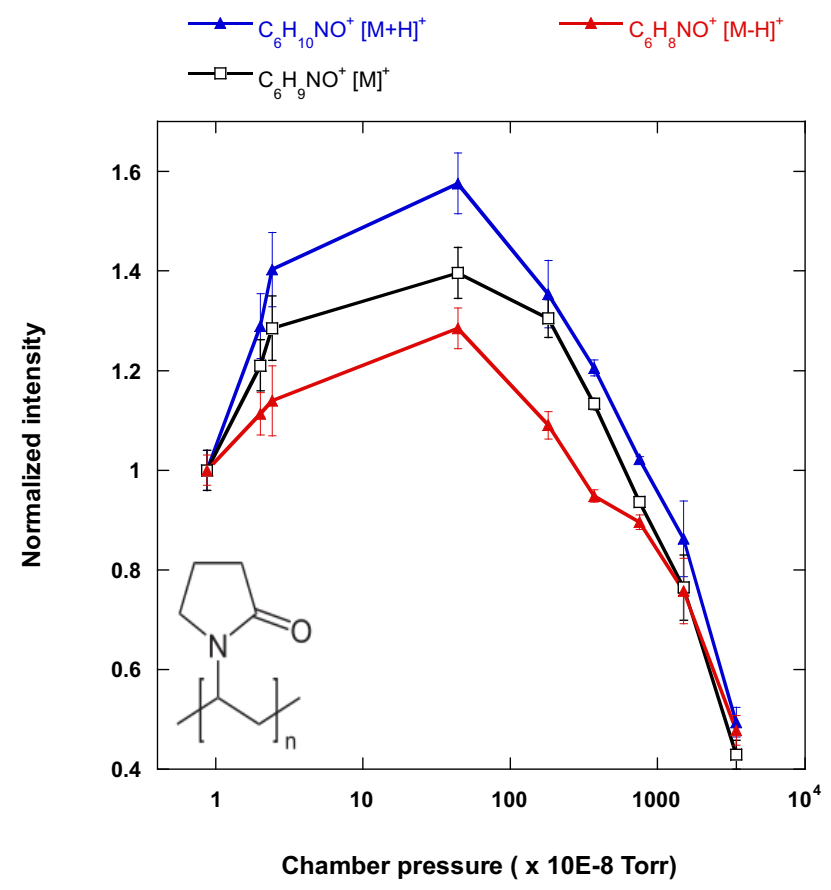

Figure 3. Chamber pressure dependence of the relative $[\mathrm{M}]^{+},[\mathrm{M}-$ $\mathrm{H}]^{+}$, and $[\mathrm{M}+\mathrm{H}]^{+}$ion intensities of PVP upon $\mathrm{H}_{2} \mathrm{O}$ flooding $(12 \mathrm{keV}$ $\mathrm{Ga}^{+}$bombardment). The measured values are normalized to those obtained under $\mathrm{Ga}^{+}$bombardment without flooding. The bottom-left inset shows the chemical formula of PVP.

Figure 4 for an Irgafos sample. In the same way that it appeared for the water vapor injection, the increase of the $\mathrm{D}_{2} \mathrm{O}$ vapor pressure induces the increase of the deuterated molecule signal until a maximum is reached, at $\sim 10^{-6}$ Torr. Due to the low abundance of free deuterium ions in toluene, which was used as solvent for the Irgafos, the formation of the deuterated molecule

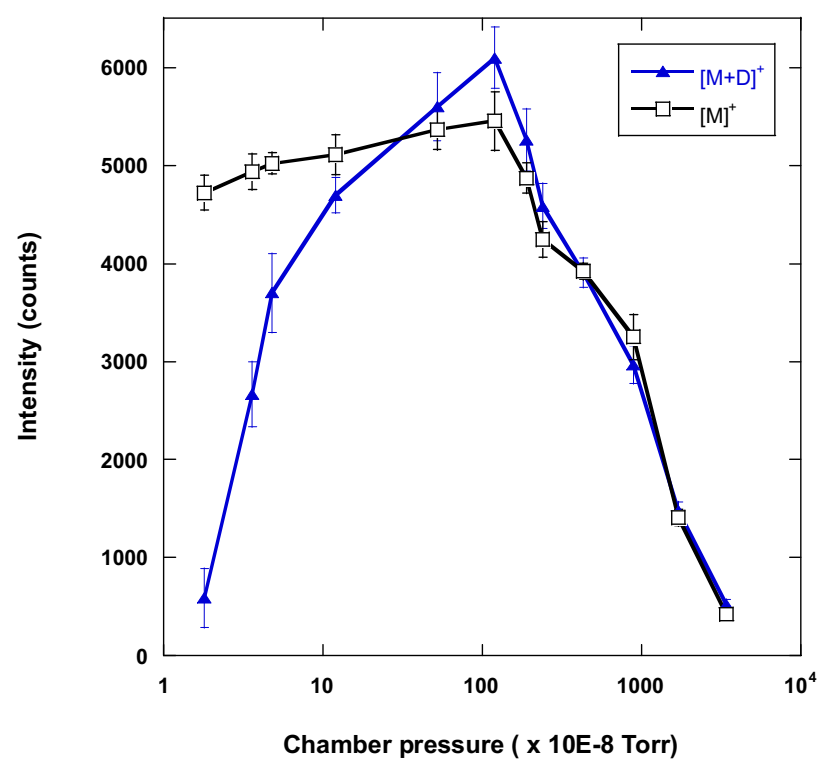

Figure 4. Chamber pressure dependence of the absolute intensity of deuterated ion $[\mathrm{M}+\mathrm{D}]^{+}$upon $\mathrm{D}_{2} \mathrm{O}$ flooding $\left(12 \mathrm{keV} \mathrm{Ga}{ }^{+}\right.$ bombardment) for the Irgafos 168 . 
ion must be caused upon ionization in the presence of $\mathrm{D}_{2} \mathrm{O}$ vapor. The enhancement of $[\mathrm{M}+\mathrm{D}]^{+}$peak is clear evidence supporting the transfer of deuterium from $\mathrm{D}_{2} \mathrm{O}$ in the region surrounding the departing molecules. Because the local pressure is relatively high, $\mathrm{D}_{2} \mathrm{O}$ is probably adsorbed onto the surface, and may act as a matrix or produce an additional source of deuterons by chemical interaction. On the other hand, deuteron exchanges occurring between the desorbed fragments and the $\mathrm{D}_{2} \mathrm{O}$ vapor molecules in the gas phase cannot be excluded. It should be mentioned that $[\mathrm{M}+\mathrm{H}]^{+}$and $[\mathrm{M}+3]^{+}$ions are also detected, indicating an $\mathrm{H} / \mathrm{D}$ exchange, which could be due to the formation of fragments in the sputtering zone. Nevertheless, their corresponding enhancements are negligible compared with the observed enhancement for $[\mathrm{M}+\mathrm{D}]^{+}$.

\section{Conclusion}

In this article, we have demonstrated a simple but efficient method to improve the analytical performance in organic SIMS, using water vapor injection near the sample surface. A significant enhancement of the positive secondary ion intensities was observed for organic materials irradiated with $\mathrm{Ga}^{+}$ions in the presence of $\mathrm{H}_{2} \mathrm{O}$ gas. In addition, our results show that the enhancement depends on the type of secondary ion and that the formation of protonated ions is specifically favored. For the low molecular weight additive Irgafos 168, the normalized $[\mathrm{M}+\mathrm{H}]^{+}$intensity increased by one order of magnitude upon $\mathrm{H}_{2} \mathrm{O}$ flooding. The enhancement factors are lower with high molecular weight polymers. Nevertheless, the intensity of the protonated monomer ions is also enhanced preferentially in comparison with those of the deprotonated and the bare monomer ions. TOF-SIMS analyses of Irgafos 168 upon $\mathrm{D}_{2} \mathrm{O}$ flooding (or $\mathrm{H}_{2} \mathrm{O}$ flooding) demonstrate that the enhancement of the deuterated (or protonated) ion intensity is caused by deuteron (or proton) transfer from the water molecules. Advantages of this method are that it can be easily used whatever the kind of the organic sample and it can be set up independently of the operating ion source. Our current set up still needs optimization, for instance in terms of differential pumping, pressure measurement, or nature of the reacting gas. Therefore, we hope to reach higher ion yield enhancements. Finally, we also plan to check whether the signal enhancements measured upon $\mathrm{Ga}^{+}$ion bombardment also occur with cluster primary ions, such as $\mathrm{C}_{60}{ }^{+}$.

\section{Acknowledgments}

The authors acknowledge support for this work by the European Community under the FP7 project 3D-Nanochemiscope (grant agreement: CP-TP 200613-2). A.D. thanks the Fonds National de la Recherche Scientifique (FNRS) for financial support.

\section{References}

1. Bletsos, I. V.; Hercules, D. M.; VanLeyen, D.; Hagenhoff, B.; Niehuis, E.; Benninghoven, A. Molecular Weight Distributions of Polymers Using Time-of-Flight Secondary Ion Mass Spectrometry. Anal. Chem. 1991, 63, 1953-1960.

2. Delcorte, A.; Wojciechowski, I.; Gonze, X.; Garrison, B. J.; Bertrand, P. Single and Double Cationization of Organic Molecules in SIMS. Int. J. Mass Spectrom. 2002, 214, 213-232.

3. Médard, N.; Poleunis, C.; Vanden Eynde, X.; Bertrand, P. Characterization of Additives at Polymer Surfaces by TOF-SIMS. Surf. Interface Anal. 2002, 34, 565-569.

4. Belu, A. M.; Graham, D. J.; Castner, D. G. Time-of-Flight Secondary Ion Mass Spectrometry: Techniques and Applications for the Characterization of Biomaterial Surfaces. Biomaterials 2003, 24, 3635-3653.

5. Davies, M. C.; Lynn, R. A. A review: Secondary Ion Mass Spectrometry (SIMS) of Polymeric Biomaterials. Clin. Mater. 1990, 5, 97-114.

6. Wu, K. J.; Odom, R. W. Matrix-Enhanced Secondary Ion Mass Spectrometry: A Method for Molecular Analysis of Solid Surfaces. Anal. Chem. 1996, 68, 873-882.

7. Hanton, S. D.; Cornelio-Clark, P. A.; Owens, K. G. Investigations of Matrix-Assisted Laser Desorption/Ionization Sample Preparation by Time-of-Flight Secondary Ion Mass Spectrometry. J. Am. Soc. Mass Spectrom. 1999, 10, 104-111.

8. Wehbe, N.; Mouhib, T.; Prabhakaran, A.; Bertrand, P.; Delcorte, A. Influence of the Organic Layer Thickness in (Metal-Assisted) Secondary Ion Mass Spectrometry Using $\mathrm{Ga}^{+}$and $\mathrm{C}_{60}{ }^{+}$Projectiles. J. Am. Soc. Mass Spectrom. 2009, 20, 2294-2303.

9. Delcorte, A.; Médard, N.; Bertrand, P. Organic Secondary Ion Mass Spectrometry: Sensitivity Enhancement by Gold Deposition. Anal. Chem. 2002, 74, 4955-4968.

10. Altelaar, A. F.; Klinkert, I.; Jalink, K. de Lange, R. P.; Adan, R. A. Heeren, R. M.; Piersma, S. R. Gold-Enhanced Biomolecular Surface Imaging of Cells and Tissue by SIMS and MALDI Mass Spectrometry. Anal. Chem. 2006, 78, 734-742.

11. Van Stipdonk, M. J.; Harris, R. D.; Schweikert, E. A. A Comparison of Desorption Yields from $\mathrm{C}^{+}{ }_{60}$ to Atomic and Polyatomic Projectiles at keV Energies. Rapid Commun. Mass Spectrom. 1996, 10, 1987-1991.

12. Gillen, G.; Roberson, S. Preliminary Evaluation of an $\mathrm{SF}_{5}{ }^{+}$Polyatomic Primary Ion Beam for Analysis of Organic Thin Films by Secondary Ion Mass Spectrometry. Rapid Commun. Mass Spectrom. 1998, 12, 1303-1312.

13. Kollmer, F. Cluster Primary Ion Bombardment of Organic Materials. Appl. Surf. Sci. 2004, 231/232, 153-158.

14. Weibel, D.; Wong, S.; Lockyer, N.; Blenkinsopp, P.; Hill, R.; Vickerman, J. C. $\mathrm{A} \mathrm{C}_{60}$ Primary Ion Beam System for Time of Flight Secondary Ion Mass Spectrometry: Its Development and Secondary Ion Yield Characteristics. Anal. Chem. 2003, 75, 1754-1764.

15. Seah, M. P.; Green, F. M.; Gilmore, I. S. Cluster Primary Ion Sputtering: Secondary Ion Intensities in Static SIMS of Organic Materials. J. Phys. Chem. C 2010, 114, 5351-5359.

16. Wittmaack, K.; Szymczak, W.; Hoheisel, G.; Tuszynski, W. Timeof-flight Secondary Ion Mass Spectrometry of Matrix-Diluted Oligoand Polypeptides Bombarded with Slow and Fast Projectiles: Positive and Negative Matrix and Analyte Ion Yields, Background Signals, and Sample Aging. J. Am. Soc. Mass Spectrom. 2000, 11, 553-563.

17. Houssiau, L.; Douhard, B.; Mine, N. Molecular Depth Profiling of Polymers with Very Low Energy Ions. Appl. Surf. Sci. 2008, 255, 970-972.

18. Cramer, H.G.; Grehl, T.; Kollmer, F.; Moellers, R.; Niehuis, E.; Rading, D. Depth Profiling of Organic Materials using Improved Ion Beam Conditions. Appl. Surf. Sci. 2008, 255, 966-969.

19. Brison, I.; Conard, T.; Vandervorst, W. Houssiau, L. Cesium/Xenon Dual Beam Depth Profiling with TOF-SIMS: Measurement and Modeling of $\mathrm{M}^{+}, \mathrm{MCs}^{+}$, and $\mathrm{M}_{2} \mathrm{Cs}_{2}{ }^{+}$Yields. Appl. Surf. Sci. 2004, 231/232, $749-753$.

20. Benninghoven, A.; Rudenauer, F. G.; Werner, H. Secondary Ion Mass Spectrometry; John Wiley and Sons: New York, 1987; p. 217-260

21. Reuter, W. Secondary Ion Emission from Metal Targets under Carbon Trifluoride Ion $\left(\mathrm{CF}_{3}{ }^{+}\right)$and Oxygen Ion $\left(\mathrm{O}_{2}{ }^{+}\right)$Bombardment. Anal. Chem. 1987, 59, 2081-2087.

22. Gao, Y.; Migeon, H. M.; Juhel, M.; Lecart, J. Enhanced SIMS Analysis Performance by $\mathrm{CCl}_{4}$ Flooding Technique. Surf. Interface Anal. 1993, 20, $716-718$.

23. Sielanko, J.; Filiks, J.; Sowa, M.; Zinkiewicz, J.; Drewniak, M. The Freon Flooding Technique in SIMS Analysis. Vacuum 1995, 46, 1459-1460.

24. Stark, T. J.; Shedd, G. M.; Vitarelli, J.; Griffis, D. P.; Russell, P. E. $\mathrm{H}_{2} \mathrm{O}$ Enhanced Focused Ion Beam Micromachining. J. Vac. Sci. Technol. B 1995, 13, 2565-2569.

25. Conlan, X. A.; Lockyer, N. P.; Vickerman, J. C. Is Proton Cationization Promoted by Polyatomic Primary Ion Bombardment During Time-ofFlight Secondary Ion Mass Spectrometry Analysis of Frozen Aqueous Solutions? Rapid Commun. Mass Spectrom. 2006, 20, 1327-1334.

26. Cliff, B.; Lockyer, N.; Jungnickel, H.; Stephens, G.; Vickerman, J. C. Probing Cell Chemistry with Time-of-Flight Secondary Ion Mass Spectrometry: Development and Exploitation of Instrumentation for Studies of Frozen-Hydrated Biological Material. Rapid Commun. Mass Spectrom. 2003, 17, 2163-2167. 
27. Roddy, T. P.; Cannon, D. M. Jr.; Ostrowski, S. G.; Ewing, A. G.; Winograd, N. Proton Transfer in Time-of-Flight Secondary Ion Mass Spectrometry Studies of Frozen-Hydrated Dipalmitoylphosphatidylcholine. Anal. Chem. 2003, 75, 4087-4094.
28. Schueler, B.; Sander, P.; Reed, D. A. A Time-of-Flight Secondary Ion Microscope. Vacuum 1990, 41, 1661-1664.

29. McIntyre, S. K.; Alam, T. M. ${ }^{17} \mathrm{O}$ NMR Investigation of Phosphite Hydrolysis Mechanisms. Magn. Reson. Chem. 2007, 45, 1022-1026. 